\title{
Composição e diversidade arbórea nas quadras urbanizadas de Palmas, Tocantins
}

\author{
Arboreous composition and diversity in the urbanized blocks of Palmas, \\ Tocantins state
}

\author{
Renato Torres Pinheiro', Dianes Gomes Marcelino" ${ }^{\mathrm{II}}$, Dieyson Rodrigues Moura ${ }^{\mathrm{III}}$
}

\begin{abstract}
Resumo
O processo de urbanização é o principal elemento transformador dos ambientes urbanos. Com a implantação das estruturas que compõe o ambiente urbano (ruas, avenidas, prédios, etc.) a arborização autóctone é indiscriminadamente suprimida em praticamente todas as cidades brasileiras, promovendo a perda de biodiversidade e alteração na qualidade de vida das pessoas que nestas habitam. O objetivo deste trabalho foi quantificar a arborização e avaliar sua composição e diversidade arbórea nas quadras urbanizadas da cidade de Palmas/TO. O inventário da vegetação ocorreu nas áreas verdes e em 50\% das ruas de 33 quadras residenciais urbanizadas de Palmas, sendo coletados dados de todos os indivíduos arbóreos em cada um desses locais. Foram amostrados 16.294 indivíduos arbóreos de 200 espécies e 47 famílias botânicas nas quadras residenciais urbanizadas de Palmas. As espécies nativas do Cerrado foram as mais frequentes, com $51,28 \%$ dos indivíduos amostrados. A diversidade de espécies foi elevada $\left(\mathrm{H}^{\prime}=4,046\right)$ e significativamente maior $(\mathrm{t}=12,364, \mathrm{p}<0,001)$ nas áreas verdes $\left(\mathrm{H}^{\prime}=3,892\right)$ em relação às ruas $\left(\mathrm{H}^{\prime}=3,572\right)$. Comparado a outros centros urbanos, Palmas se destaca em termos de diversidade de espécies nativas do Cerrado, estando esse fator diretamente relacionado à presença de áreas verdes não edificantes em cada quadra residencial, devendo esses espaços ser conservados e incrementados com um maior número de espécies nativas, proporcionando a manutenção da biodiversidade e melhoria da qualidade de vida e bem estar dos moradores de cada local.
\end{abstract}

Palavras-chave: Arboricultura; Urbanização; Paisagem urbana; Biodiversidade

\begin{abstract}
The process of urbanization is the main transformational element of urban environments. Along with the implementation of structures that make up the urban environment (streets, avenues, buildings, etc.), natural stands of trees are indiscriminately removed in practically all Brazilian cities, promoting the loss of biodiversity and degrading the quality of life of the people living in these cities. The objective of this work was to evaluate the changes in vegetation and species diversity during the urbanization process of the city of Palmas, TO state. The vegetation inventory occurred in green areas and in $50 \%$ of the streets of 33 urban residential blocks, with data collected from all individual trees in each of these sites. A total of 16,294 trees were sampled in the urbanized residential blocks of Palmas, which came from 200 species and 47 botanical families. In general, the native species of the Cerrado biome were the most frequent ones, comprising $51.28 \%$ of the individuals. The species diversity was high $\left(\mathrm{H}^{\prime}=4.046\right)$ and it was statistically higher $(t=12.364, p<0.001)$ in green spaces $\left(H^{\prime}=3.892\right)$ than in the streets $\left(H^{\prime}=3.572\right)$. Compared to other urban centers, Palmas stands out in terms of the diversity of native tree species of Cerrado, with its diversity directly relating to the presence of empty green space in each residential block. These open spaces should be conserved and increased to promote a greater number of species that will maintain the biodiversity and improve the quality of life and well-being of the city inhabitants.
\end{abstract}

Keywords: Arboriculture; Urbanization; Urban landscape; Biodiversity

\footnotetext{
Biólogo, Dr., Curso de Medicina, Universidade Federal do Tocantins, Campus de Palmas, 109 Norte, Av. NS-15, ALCNO 14, Plano Diretor Norte, CEP 77001-090, Palmas (TO), Brasil. renaxas@ hotmail.com (ORCID: 0000-0002-5799-0872)

II Engenheiro Ambiental, MSc., Ecótono Engenharia, Rua D, 49, Casa 04, Cidade Nova, CEP 68515-000, Parauapebas (PA), Brasil. dianes.gomes@ gmail.com (ORCID: 0000-0001-8678-7243)

III Engenheiro Ambiental, MSc., Ecótono Engenharia, 104 Norte, NE 03, Lote 38, Sala 03, Plano Direto Norte, CEP 77006-018, Palmas (TO), Brasil. contato@ecotono.eng.br(ORCID: 0000-0001-9158-677X)
} 


\section{Introdução}

A arborização é uma importante parte da infraestrutura urbana, provendo uma série de serviços ecossistêmicos fundamentais para o bem estar humano. Os benefícios associados à arborização urbana vão muito além dos estéticos e podem ser divididos em três categorias: ambientais, relacionados à melhoria do ar, redução das ilhas de calor, ou ao aumento da biodiversidade; sociais, reduzindo o estresse ou estimulando a convivência social; e econômicos, reduzindo o consumo de energia ou aumentado o valor da propriedade (MORGENROTH et al., 2016).

Em nosso país, o paisagismo urbano seguiu e, em muitos casos, ainda segue a escola européia do século XIX, valorizando atributos estéticos e a introdução de muitas espécies exóticas (SANTOS; BERGALLO; ROCHA, 2008). Nesse sentido, a arborização das cidades brasileiras é muito similar entre si, havendo uma replicação de padrões e de espécies encontradas em cidades de norte a sul do país, independente de seu porte (SANTOS; BERGALLO; ROCHA, 2008; MORO; WESTERKAMP; ARAÚJO, 2014). Algo contraditório no país detentor da maior diversidade biológica global (LEWINSOHN; PRADO, 2002) e em função do amplo reconhecimento sobre os aspectos positivos relacionados às espécies nativas (MORO; WESTERKAMP; ARAÚJO, 2014), o que reforça a necessidade de reavaliar os modelos vigentes de paisagismo urbano adotados no país.

Um exemplo do modelo de paisagismo tradicional foi o implantado em Palmas-TO, a última cidade brasileira planejada, erguida a partir de 1989 em uma área de Cerrado preservado, para ser a capital do Estado do Tocantins. Segundo Teixeira (2009), a cidade foi planejada sob um ponto de vista humanístico e ecológico, sendo que a preservação ambiental foi um dos pilares para sua concepção, onde as áreas com vegetação nativa nos fundos de vale seriam protegidas durante sua implantação e cada quadra residencial seria composta por áreas verdes não edificantes, proporcionando um ambiente com temperatura mais amena e consequentemente melhor qualidade de vida para a população.

Bargos e Matias (2011) realizaram um estudo de revisão e proposta conceitual para as áreas verdes urbanas e a definiram como um espaço livre urbano composto por vegetação arbórea e arbustiva, com solo livre de edificações e superfícies impermeabilizantes, de acesso público ou não, e que exerçam funções ecológicas, estéticas e de lazer. Entretanto, o que se verificou durante o processo de implantação de Palmas-TO foi a supressão parcial ou total de extensas áreas de vegetação nativa do Cerrado e o plantio de espécies arbóreas exóticas ao Cerrado (ADORNO; FIGHERA, 2005). A cidade apresenta características singulares para avaliar as mudanças sofridas pela paisagem natural durante o processo de urbanização. Assim, neste estudo quantificamos a arborização e avaliamos sua composição e diversidade nas quadras residenciais urbanizadas de Palmas-TO e discutimos sobre a importância das áreas verdes não edificantes para a promoção do bem estar social e manutenção da biodiversidade local.

\section{Material e método}

\section{Caracterização da área de estudo}

Palmas-TO está localizada na região central do Estado do Tocantins, sob o paralelo $10^{\circ} 11^{\prime} 04^{\prime \prime}$ Sul e do meridiano $48^{\circ} 20^{\prime} 01^{\prime \prime}$ Oeste, tendo população estimada em 2018 de 291.855 habitantes (IBGE, 2010). A paisagem local é formada por vegetação típica do Cerrado, variando entre fitofisionomias florestais, campestres e savânicas. O clima é caracterizado por uma estação seca, entre os meses de maio a setembro; e outra chuvosa, entre os meses de outubro a abril. O índice pluviométrico varia de 1.500 a $1.900 \mathrm{~mm} /$ ano e a temperatura média anual é de $26^{\circ} \mathrm{C}$, sendo a média mais quente de $36^{\circ} \mathrm{C}$ em setembro, e a mais fria em julho, com mínima de $15,5^{\circ} \mathrm{C}$ 
(PALMAS, 2015).

O modelo de ordenamento espacial de Palmas segue o exemplo de outras cidades planejadas, estando dividida em áreas industriais, comerciais e residenciais, estas últimas apresentam em média dimensões de $700 \times 700 \mathrm{~m}$, planejamento interno distinto e capacidade para abrigar entre 8 a 12 mil habitantes (TEIXEIRA, 2009). Em geral, as quadras residenciais possuem escola, unidade básica de saúde, áreas comerciais, áreas para esporte e lazer e áreas verdes não edificantes (AVNE). As áreas verdes de Palmas são regidas pela Lei de Uso do Solo de PalmasTO, Lei n. 386/1993, alterada pela Lei n. 1070/2001, art. 15, parágrafo 5º e definida como: "Zona de uso caracterizada pela otimização das condições ecológicas do meio ambiente, sendo admitido o desenvolvimento de atividades de lazer compatíveis com essas condições”.

Figura 1 - Esquema do Plano Diretor de Palmas, TO, evidenciando as quadras amostradas

Figure 1 - Scheme of the Master Plan of Palmas, TO state, showing the sampled blocks

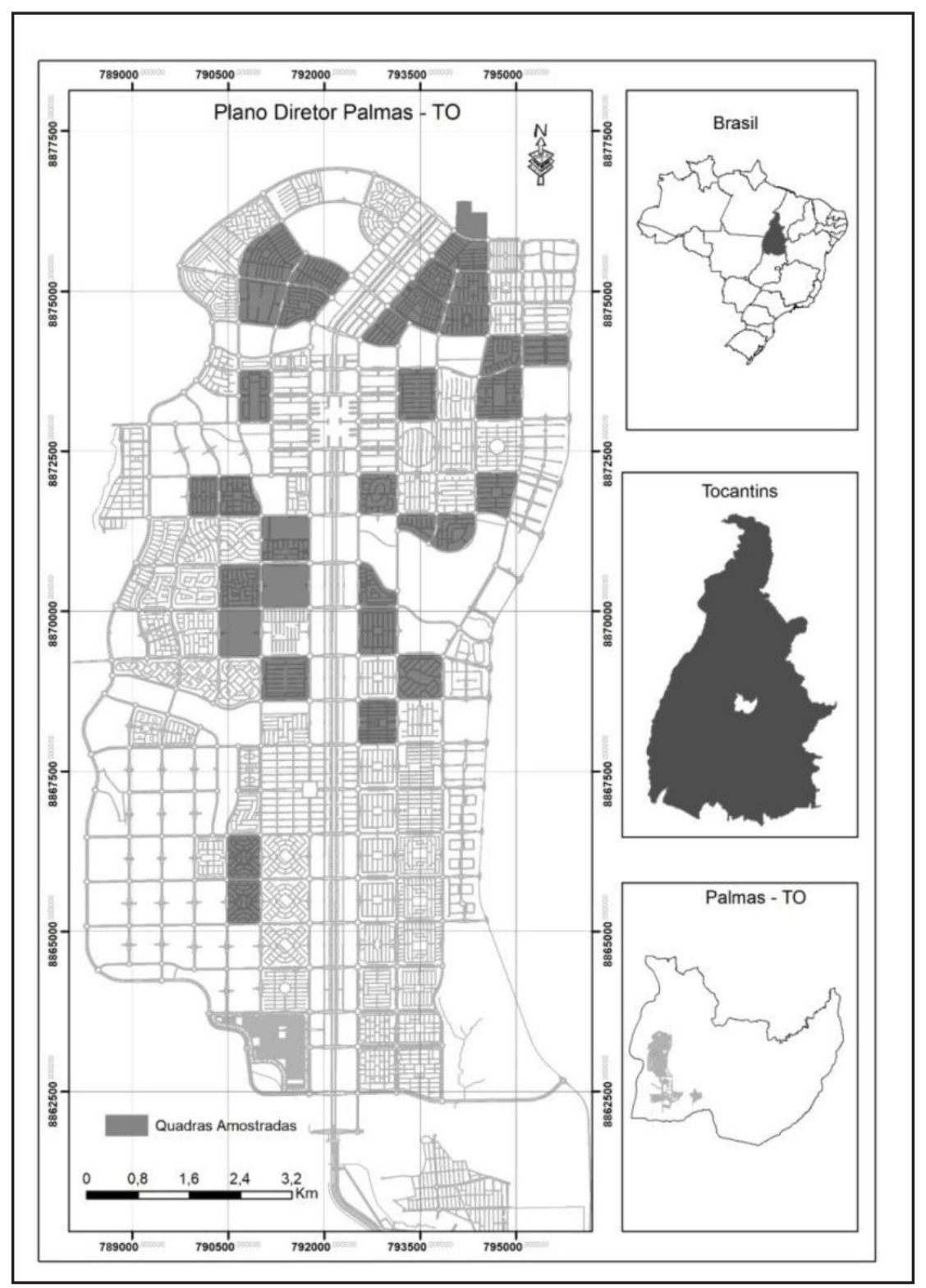

Fonte: Instituto de Planejamento Urbano de Palmas (2007).

Adaptado por Dieyson Moura (2019). 


\section{Coleta e análise dos dados}

Os dados foram coletados entre fevereiro e dezembro de 2015, nas áreas verdes e ruas de 33 das 63 quadras residenciais urbanizadas e asfaltadas das quatro regiões da cidade de PalmasTO, selecionadas aleatoriamente: Área Residencial Sudoeste - ARSO: 205S, 207S, 303S, 403S, 405S, 505S, 603S, 1005S e 1105S; Área Residencial Sudeste - ARSE: 204S, 210S, 306S, 308S, 404S, 504S, 606S e 704S; Área Residencial Noroeste - ARNO: 105N, 303N, 305N, 403N, 405N e Área Residencial Nordeste - ARNE: 106N, 110N, 112N, 208N, 304N, 404N, 406N, 504N, 506N, 604N e $608 \mathrm{~N}$ e incorporados em um coletor de dados Mesa Juniper System ${ }^{\circledR}$.

Foram coletados dados de todos os indivíduos arbóreos relativos à espécie (nome científico e popular) e origem, sendo as espécies arbóreas classificadas em: nativas do cerrado, espécies autóctones ou com ocorrência comprovada no bioma cerrado, espécies nativas brasileiras, mas com ocorrência fora do bioma cerrado e espécies originárias de outros países. Técnicas analíticas descritivas foram utilizadas para organizar e investigar os dados, sendo obtidos dados referentes à riqueza e porcentagem de ocorrência $\left(\mathrm{ni}^{\star} 100 / \mathrm{N}\right)$, para cada categoria. Para estimar e comparar a diversidade de espécies entre as áreas verdes e ruas das quadras urbanizadas, utilizou-se uma medida não paramétrica de diversidade (Equação 1), o Índice de Shannon (H’) (MAGURRAN, 2011). Para comparação estatística aplicou-se o teste "t" de Hutcheson (1970).

$$
H^{\prime}=-\sum p_{i} \ln p_{i}
$$

Equação 1

As espécies vegetais foram identificadas em campo, havendo dúvidas foram encaminhadas amostras ao Herbário da Universidade Federal do Tocantins, Campus de Porto Nacional. Informações taxonômicas das espécies brasileiras foram obtidas em Lorenzi (2002; 2014), na base de dados do Jardim Botânico do Rio de Janeiro (JARDIM BOTÂNICO, 2018) e das espécies estrangeiras em The Plant List (2013).

\section{Resultados}

Nas quadras residenciais urbanizadas de Palmas foram amostrados 16.294 indivíduos arbóreos de 200 espécies e 47 famílias botânicas. Nas ruas foram contabilizados 4.763 indivíduos de 144 espécies e nas áreas verdes 11.531 indivíduos de 183 espécies.

As cinco espécies mais frequentes foram o cajú Anacardium occidentale L. com 1.512 indivíduos, o pequi Caryocar brasiliense Cambess. com 1.371, a manga Mangifera indica L. com 1.293, o oiti Licania tomentosa (Benth.) Fritsch com 1.243 e o ipê-roxo Handroanthus impetiginosus (Mart. ex DC.) Mattos com 832 indivíduos.

As espécies nativas do Cerrado foram as mais frequentes, correspondendo a $51,28 \%$ do total de indivíduos arbóreos, dos quais $89,36 \%$ estão situados nas áreas verdes e 10,64\% nas ruas. As espécies exóticas estrangeiras contabilizaram 33,17\% dos indivíduos, sendo $57,21 \%$ nas áreas verdes e $42,79 \%$ nas ruas, enquanto as espécies brasileiras exóticas ao Cerrado contabilizaram $15,55 \%$ dos indivíduos, sendo $38,40 \%$ nas áreas verdes e $61,60 \%$ nas ruas (Tabela 1 ). 
Tabela 1 - Famílias, espécies, nome popular, origem e porcentagem de ocorrência das árvores encontradas nas ruas e áreas verdes das quadras urbanizadas de Palmas/TO

Table 1 - Families, species, name, origin and percentage of occurrence of the trees found in the streets and green areas of the urbanized blocks of Palmas/TO state

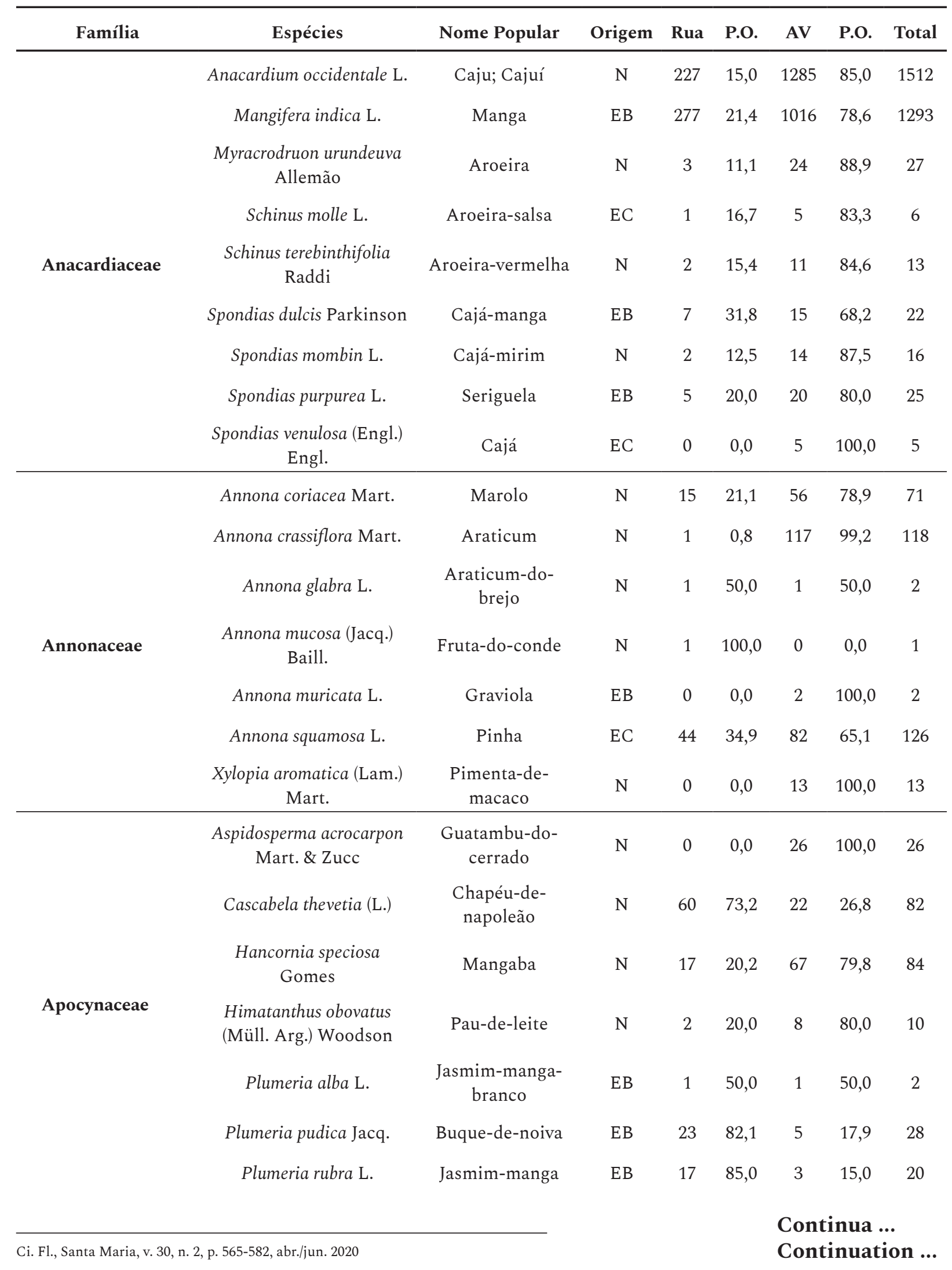


Tabela 1 - Continuação ...

Table 1 - Continuation ...

\begin{tabular}{|c|c|c|c|c|c|c|c|c|}
\hline Família & Espécies & Nome Popular & Origem & Rua & P.O. & AV & P.O. & Total \\
\hline Araliaceae & $\begin{array}{l}\text { Schefflera morototonii } \\
\text { (Aubl.) Maguire et al. }\end{array}$ & Mandioqueiro & $\mathrm{N}$ & 0 & 0,0 & 8 & 100,0 & 8 \\
\hline Araucariaceae & $\begin{array}{c}\text { Araucaria angustifolia } \\
\text { (Bertol.) O. Kuntze }\end{array}$ & Araucária & $\mathrm{EC}$ & 2 & 100,0 & 0 & 0,0 & 2 \\
\hline & $\begin{array}{l}\text { Acrocomia aculeata (Jacq.) } \\
\text { Lodd. ex Mart. }\end{array}$ & Macaúba & $\mathrm{N}$ & 6 & 17,1 & 29 & 82,9 & 35 \\
\hline & $\begin{array}{c}\text { Attalea phalerata Mart. ex } \\
\text { Spreng. }\end{array}$ & Bacuri & $\mathrm{N}$ & 0 & 0,0 & 7 & 100,0 & 7 \\
\hline & $\begin{array}{c}\text { Attalea speciosa Mart. ex } \\
\text { Spreng. }\end{array}$ & Babaçu & $\mathrm{N}$ & 1 & 33,3 & 2 & 66,7 & 3 \\
\hline & $\begin{array}{l}\text { Bismarckia nobilis } \\
\text { Hildebr. \& Wendl. }\end{array}$ & Palmeira-azul & $\mathrm{EB}$ & 7 & 63,6 & 4 & 36,4 & 11 \\
\hline & $\begin{array}{l}\text { Carpentaria acuminata }(\mathrm{H} . \\
\text { Wendl. \& Drude) Becc }\end{array}$ & Carpentaria & EB & 7 & 100,0 & 0 & 0,0 & 7 \\
\hline & Caryota urens L. & $\begin{array}{l}\text { Palmeira-rabo-de- } \\
\text { peixe }\end{array}$ & EB & 30 & 93,8 & 2 & 6,3 & 32 \\
\hline & Cocos nucifera L. & Coco-da-bahia & EC & 126 & 41,0 & 181 & 59,0 & 307 \\
\hline & $\begin{array}{l}\text { Dypsis decaryi (Jum.) } \\
\text { Beentje \& J. Dransf. }\end{array}$ & $\begin{array}{l}\text { Palmeira- } \\
\text { triangular }\end{array}$ & EB & 66 & 93,0 & 5 & 7,0 & 71 \\
\hline \multirow{11}{*}{ Arecaceae } & $\begin{array}{c}\text { Dypsis lutescens } \\
\text { (H.Wendl.) Beentje \& } \\
\text { J.Dransf. }\end{array}$ & Areca-bambu & EB & 68 & 93,2 & 5 & 6,8 & 73 \\
\hline & $\begin{array}{c}\text { Dypsis madagascariensis } \\
\text { (Becc.) Beentje \& J. } \\
\text { Dransf. }\end{array}$ & Areca-locuba & EB & 163 & 79,5 & 42 & 20,5 & 205 \\
\hline & Elaeis guineensis Jacq. & Dendê & $\mathrm{EB}$ & 2 & 100,0 & 0 & 0,0 & 2 \\
\hline & Euterpe oleracea Mart. & Açai & $\mathrm{N}$ & 17 & 58,6 & 12 & 41,4 & 29 \\
\hline & Mauritia flexuosa L.f. & Buriti & $\mathrm{N}$ & 2 & 50,0 & 2 & 50,0 & 4 \\
\hline & Oenocarpus bacaba Mart. & Bacaba & $\mathrm{N}$ & 4 & 66,7 & 2 & 33,3 & 6 \\
\hline & $\begin{array}{c}\text { Phoenix roebelenii } \\
\text { O'Brien }\end{array}$ & Palmeira-fênix & $\mathrm{EB}$ & 246 & 96,1 & 10 & 3,9 & 256 \\
\hline & $\begin{array}{l}\text { Phoenix sylvestris (L.) } \\
\text { Roxb. }\end{array}$ & Tamareira-indiana & EB & 5 & 83,3 & 1 & 16,7 & 6 \\
\hline & $\begin{array}{l}\text { Roystonea oleracea (Jacq.) } \\
\text { O.F. Cook. }\end{array}$ & Palmeira-imperial & EB & 66 & 91,7 & 6 & 8,3 & 72 \\
\hline & Syagrus cocoides Mart. & Pati & $\mathrm{N}$ & 0 & 0,0 & 2 & 100,0 & 2 \\
\hline & $\begin{array}{c}\text { Syagrus oleracea (Mart.) } \\
\text { Becc }\end{array}$ & Gueroba & $\mathrm{N}$ & 46 & 43,4 & 60 & 56,6 & 106 \\
\hline
\end{tabular}


Tabela 1 - Continuação ...

Table 1 - Continuation ...

\begin{tabular}{|c|c|c|c|c|c|c|c|c|}
\hline Família & Espécies & Nome Popular & Origem & Rua & P.O. & AV & P.O. & Total \\
\hline \multirow{4}{*}{ Arecaceae } & $\begin{array}{c}\text { Syagrus picrophylla Barb. } \\
\text { Rodr. }\end{array}$ & Licuri & EC & 15 & 55,6 & 12 & 44,4 & 27 \\
\hline & $\begin{array}{l}\text { Syagrus romanzoffiana } \\
\text { (Cham.) Glassman }\end{array}$ & Jerivá & $\mathrm{N}$ & 19 & 82,6 & 4 & 17,4 & 23 \\
\hline & $\begin{array}{l}\text { Washingtonia robusta } \\
\text { H.Wendl }\end{array}$ & Washingtonia & EB & 24 & 82,8 & 5 & 17,2 & 29 \\
\hline & $\begin{array}{c}\text { Wodyetia bifurcata A. K. } \\
\text { Irvine }\end{array}$ & $\begin{array}{c}\text { Palmeira-rabo-de- } \\
\text { raposa }\end{array}$ & EB & 21 & 100,0 & 0 & 0,0 & 21 \\
\hline Asteraceae & $\begin{array}{l}\text { Piptocarpha rotundifolia } \\
\text { (Less.) Baker }\end{array}$ & Coração-de-negro & $\mathrm{N}$ & 0 & 0,0 & 10 & 100,0 & 10 \\
\hline \multirow[t]{11}{*}{ Bignoniaceae } & Crescentia cujete L. & Cabaceira & $\mathrm{N}$ & 0 & 0,0 & 8 & 100,0 & 8 \\
\hline & $\begin{array}{c}\text { Handroanthus } \\
\text { chrysotrichus (Mart. ex } \\
\text { DC.) Mattos }\end{array}$ & $\begin{array}{l}\text { Ipê-amarelo- } \\
\text { cascudo }\end{array}$ & EC & 11 & 36,7 & 19 & 63,3 & 30 \\
\hline & $\begin{array}{c}\text { Handroanthus } \\
\text { heptaphyllus (Vell.) Matos }\end{array}$ & Ipê-roxo & EC & 1 & 100,0 & 0 & 0,0 & 1 \\
\hline & $\begin{array}{c}\text { Handroanthus } \\
\text { impetiginosus (Mart. ex } \\
\text { DC.) Mattos }\end{array}$ & Ipê-roxo & $\mathrm{N}$ & 197 & 23,7 & 635 & 76,3 & 832 \\
\hline & $\begin{array}{l}\text { Handroanthus serratifolius } \\
\text { (Vahl.) S. O. Grose }\end{array}$ & Pau-d'arco & $\mathrm{N}$ & 31 & 24,4 & 96 & 75,6 & 127 \\
\hline & $\begin{array}{c}\text { Spathodea campanulata } \mathrm{P} . \\
\text { Beauv. }\end{array}$ & Espatódea & EB & 0 & 0,0 & 1 & 100,0 & 1 \\
\hline & Spathodea nilotica Beauv. & Bisnagueira & EB & 1 & 100,0 & 0 & 0,0 & 1 \\
\hline & $\begin{array}{l}\text { Tabebuia aurea (Manso) } \\
\text { Benth. \& Hook. f. ex S. } \\
\text { Moore }\end{array}$ & Caraíba & $\mathrm{N}$ & 1 & 100,0 & 0 & 0,0 & 1 \\
\hline & $\begin{array}{l}\text { Tabebuia pilosa A.H. } \\
\text { Gentry }\end{array}$ & Ipê & EC & 2 & 100,0 & 0 & 0,0 & 2 \\
\hline & $\begin{array}{c}\text { Tabebuia roseoalba (Ridl.) } \\
\text { Sandwith }\end{array}$ & Ipê-branco & $\mathrm{N}$ & 0 & 0,0 & 7 & 100,0 & 7 \\
\hline & $\begin{array}{c}\text { Tecoma stans (L.) Juss. ex } \\
\text { Kunth }\end{array}$ & Falso-ipê & EB & 26 & 41,9 & 36 & 58,1 & 62 \\
\hline Bixaceae & Bixa orellana $\mathrm{L}$. & Urucum & $\mathrm{N}$ & 4 & 28,6 & 10 & 71,4 & 14 \\
\hline \multirow{2}{*}{ Calophyllaceae } & $\begin{array}{c}\text { Kielmeyera coriacea Mart. } \\
\text { \& Zucc. }\end{array}$ & Folha-santa & $\mathrm{N}$ & 0 & 0,0 & 20 & 100,0 & 20 \\
\hline & $\begin{array}{l}\text { Kielmeyera lathrophyton } \\
\text { Saddi }\end{array}$ & Pau-santo & $\mathrm{N}$ & 0 & 0,0 & 75 & 100,0 & 75 \\
\hline \multirow[t]{2}{*}{ Caryocaraceae } & $\begin{array}{l}\text { Caryocar brasiliense } \\
\text { Cambess. }\end{array}$ & Pequi & $\mathrm{N}$ & 30 & 2,2 & 1341 & 97,8 & 1371 \\
\hline & & & & & & \multicolumn{3}{|c|}{$\begin{array}{l}\text { Continua ... } \\
\text { Continuation ... }\end{array}$} \\
\hline
\end{tabular}


Tabela 1 - Continuação ...

Table 1 - Continuation ...

\begin{tabular}{|c|c|c|c|c|c|c|c|c|}
\hline Família & Espécies & Nome Popular & Origem & Rua & P.O. & AV & P.O. & Total \\
\hline \multirow{2}{*}{ Chrysobalanaceae } & $\begin{array}{l}\text { Hirtella ciliata Mart. \& } \\
\text { Zucc. }\end{array}$ & Pau-pombo & $\mathrm{N}$ & 0 & 0,0 & 1 & 100,0 & 1 \\
\hline & $\begin{array}{l}\text { Licania tomentosa } \\
\text { (Benth.) Fritsch }\end{array}$ & Oiti & EC & 1026 & 82,5 & 217 & 17,5 & 1243 \\
\hline Clusiaceae & Clusia hilariana Schltdl. & Clusia & EC & 15 & 62,5 & 9 & 37,5 & 24 \\
\hline \multirow{2}{*}{ Combretaceae } & $\begin{array}{c}\text { Buchenavia tomentosa } \\
\text { Eichler }\end{array}$ & Mirindiba & $\mathrm{N}$ & 0 & 0,0 & 4 & 100,0 & 4 \\
\hline & Terminalia catappa L. & $\begin{array}{l}\text { Sete-copas; } \\
\text { Castanhola }\end{array}$ & $\mathrm{EB}$ & 19 & 27,1 & 51 & 72,9 & 70 \\
\hline Connaraceae & $\begin{array}{l}\text { Connarus suberosus } \\
\text { Planch. }\end{array}$ & Araruta & $\mathrm{N}$ & 0 & 0,0 & 23 & 100,0 & 23 \\
\hline \multirow{2}{*}{ Cupressaceae } & Chamaecyparis sp. & Cipreste-alumi & EB & 1 & 50,0 & 1 & 50,0 & 2 \\
\hline & Cupressus sp. & Cipreste & $\mathrm{EB}$ & 56 & 94,9 & 3 & 5,1 & 59 \\
\hline \multirow{2}{*}{ Cycadaceae } & Cycas circinalis L. & Cica & EB & 105 & 89,7 & 12 & 10,3 & 117 \\
\hline & Cycas revoluta Thunb. & Sagu & EB & 63 & 90,0 & 7 & 10,0 & 70 \\
\hline \multirow{3}{*}{ Dilleniaceae } & Curatella americana L. & Lixeira & $\mathrm{N}$ & 0 & 0,0 & 18 & 100,0 & 18 \\
\hline & Davilla elliptica A.St.-Hil. & Lixeirinha & $\mathrm{N}$ & 2 & 25,0 & 6 & 75,0 & 8 \\
\hline & Dillenia indica $\mathrm{L}$. & Fruta-do-dinheiro & EB & 1 & 100,0 & 0 & 0,0 & 1 \\
\hline Ebenaceae & $\begin{array}{l}\text { Diospyros laxiocalyx } \\
\text { (Mart.) B. Walln }\end{array}$ & Caqui-do-cerrado & $\mathrm{N}$ & 0 & 0,0 & 25 & 100,0 & 25 \\
\hline Erythroxylaceae & $\begin{array}{c}\text { Erythroxylum suberosum } \\
\text { A.St.-Hil. }\end{array}$ & Cabelo-de-negro & $\mathrm{N}$ & 0 & 0,0 & 7 & 100,0 & 7 \\
\hline \multirow{5}{*}{ Euphorbiaceae } & Croton urucurana Baill. & Sangra-d'água & $\mathrm{N}$ & 2 & 12,5 & 14 & 87,5 & 16 \\
\hline & Euphorbia cotinifolia L. & Leiteiro-vermelho & $\mathrm{EB}$ & 2 & 25,0 & 6 & 75,0 & 8 \\
\hline & Euphorbia tirucalli L. & $\begin{array}{l}\text { Árvore-de-são- } \\
\text { sebastião }\end{array}$ & $\mathrm{EB}$ & 1 & 50,0 & 1 & 50,0 & 2 \\
\hline & Jatropha curcas L. & Pinhão & $\mathrm{EB}$ & 3 & 60,0 & 2 & 40,0 & 5 \\
\hline & Mabea fistulifera Mart. & Canudo-de-pito & $\mathrm{N}$ & 0 & 0,0 & 25 & 100,0 & 25 \\
\hline \multirow{5}{*}{ Fabaceae } & Acacia mangium Wild. & Acácia-australiana & EB & 2 & 28,6 & 5 & 71,4 & 7 \\
\hline & Adenanthera pavonina L. & Olho-de-pavão & $\mathrm{EB}$ & 0 & 0,0 & 7 & 100,0 & 7 \\
\hline & Albizia lebbeck (L.) Benth & Língua-de-sogra & $\mathrm{EB}$ & 1 & 50,0 & 1 & 50,0 & 2 \\
\hline & $\begin{array}{c}\text { Anadenanthera colubrina } \\
\text { (Vell.) Brenan }\end{array}$ & Angico & $\mathrm{N}$ & 9 & 21,4 & 33 & 78,6 & 42 \\
\hline & Andira cujabensis Benth. & Fruta-de-morcego & $\mathrm{N}$ & 0 & 0,0 & 64 & 100,0 & 64 \\
\hline
\end{tabular}


Tabela 1 - Continuação ...

Table 1 - Continuation ...

\begin{tabular}{|c|c|c|c|c|c|c|c|c|}
\hline Família & Espécies & Nome Popular & Origem & Rua & P.O. & AV & P.O. & Total \\
\hline & $\begin{array}{l}\text { Andira legalis (Vell.) } \\
\text { Toledo }\end{array}$ & Angelim-doce & $\mathrm{N}$ & 3 & 6,3 & 45 & 93,8 & 48 \\
\hline & $\begin{array}{c}\text { Andira vermifuga (Mart.) } \\
\text { Benth. }\end{array}$ & Angelim & $\mathrm{N}$ & 0 & 0,0 & 42 & 100,0 & 42 \\
\hline & Bauhinia purpurea L. & Pata-de-vaca-roxa & $\mathrm{EB}$ & 0 & 0,0 & 1 & 100,0 & 1 \\
\hline & Bauhinia variegata $\mathrm{L}$. & Pata-de-vaca & EB & 87 & 73,1 & 32 & 26,9 & 119 \\
\hline & $\begin{array}{l}\text { Bowdichia virgilioides } \\
\text { Kunth }\end{array}$ & Sucupira-preta & $\mathrm{N}$ & 0 & 0,0 & 117 & 100,0 & 117 \\
\hline & $\begin{array}{l}\text { Caesalpinia pulcherrima } \\
\text { (L.) Sw. }\end{array}$ & Flamboyanzinho & EB & 12 & 66,7 & 6 & 33,3 & 18 \\
\hline & Cassia fistula $\mathrm{L}$. & Canafistula & EB & 29 & 60,4 & 19 & 39,6 & 48 \\
\hline & $\begin{array}{l}\text { Cenostigma pluviosum } \\
\text { (Benth.) E. Gangnon \& G. } \\
\text { P. Lewis }\end{array}$ & Sibipiruna & EC & 38 & 60,3 & 25 & 39,7 & 63 \\
\hline & $\begin{array}{c}\text { Cenostigma tocantinum } \\
\text { Ducke }\end{array}$ & Pau-preto & $\mathrm{N}$ & 0 & 0,0 & 13 & 100,0 & 13 \\
\hline & $\begin{array}{c}\text { Copaifera langsdorffii } \\
\text { Desf. }\end{array}$ & Copaíba & $\mathrm{N}$ & 2 & 15,4 & 11 & 84,6 & 13 \\
\hline \multirow[t]{12}{*}{ Fabaceae } & $\begin{array}{c}\text { Dalbergia miscolobium } \\
\text { Benth. }\end{array}$ & $\begin{array}{l}\text { Jacarandá-do- } \\
\text { cerrado }\end{array}$ & $\mathrm{N}$ & 0 & 0,0 & 24 & 100,0 & 24 \\
\hline & $\begin{array}{c}\text { Delonix regia (Bojer ex } \\
\text { Hook.) Raf. }\end{array}$ & Flamboyant & $\mathrm{EB}$ & 13 & 36,1 & 23 & 63,9 & 36 \\
\hline & $\begin{array}{l}\text { Dimorphandra mollis } \\
\text { Benth. }\end{array}$ & Fava-d'anta & $\mathrm{N}$ & 2 & 2,0 & 97 & 98,0 & 99 \\
\hline & Dipteryx alata Vogel & Baru & $\mathrm{N}$ & 2 & 13,3 & 13 & 86,7 & 15 \\
\hline & $\begin{array}{c}\text { Enterolobium } \\
\text { contortisiliquum (Vell.) } \\
\text { Morong. }\end{array}$ & Tamboril & $\mathrm{N}$ & 1 & 4,3 & 22 & 95,7 & 23 \\
\hline & $\begin{array}{c}\text { Enterolobium gummiferum } \\
\text { (Mart.) J.F.Macbr. }\end{array}$ & Orelha-de-negro & $\mathrm{N}$ & 1 & 12,5 & 7 & 87,5 & 8 \\
\hline & Hymenaea courbaril L. & Jatobá-da-mata & $\mathrm{N}$ & 4 & 18,2 & 18 & 81,8 & 22 \\
\hline & $\begin{array}{c}\text { Hymenaea stigonocarpa } \\
\text { Mart. ex Hayne }\end{array}$ & Jatobá-do-cerrado & $\mathrm{N}$ & 1 & 1,9 & 51 & 98,1 & 52 \\
\hline & Inga capitata Desv. & Ingá-ferro & $\mathrm{N}$ & 1 & 5,0 & 19 & 95,0 & 20 \\
\hline & Inga edulis Mart. & Ingá-de-metro & $\mathrm{N}$ & 3 & 7,1 & 39 & 92,9 & 42 \\
\hline & Inga laurina (Sw.) Willd. & Ingá-branco & $\mathrm{N}$ & 4 & 19,0 & 17 & 81,0 & 21 \\
\hline & $\begin{array}{l}\text { Leucaena leucocephala } \\
\text { (Lam.) de Wit }\end{array}$ & Leucena & EB & 21 & 31,3 & 46 & 68,7 & 67 \\
\hline
\end{tabular}

Ci. Fl., Santa Maria, v. 30, n. 2, p. 565-582, abr./jun. 2020 
Tabela 1 - Continuação ...

Table 1 - Continuation ...

\begin{tabular}{|c|c|c|c|c|c|c|c|c|}
\hline Família & Espécies & Nome Popular & Origem & Rua & P.O. & AV & P.O. & Total \\
\hline \multirow{14}{*}{ Fabaceae } & $\begin{array}{l}\text { Libdibia ferrea (Mart. ex } \\
\text { Tul.) L.P.Queiroz }\end{array}$ & Pau-ferro & $\mathrm{EC}$ & 12 & 20,7 & 46 & 79,3 & 58 \\
\hline & $\begin{array}{c}\text { Machaerium acutifolium } \\
\text { Vogel }\end{array}$ & $\begin{array}{l}\text { Jacaranda-bico- } \\
\text { de-papagaio }\end{array}$ & $\mathrm{N}$ & 0 & 0,0 & 4 & 100,0 & 4 \\
\hline & $\begin{array}{c}\text { Mimosa caesalpiniifolia } \\
\text { Benth. }\end{array}$ & Sansão-do-campo & $\mathrm{N}$ & 1 & 8,3 & 11 & 91,7 & 12 \\
\hline & $\begin{array}{l}\text { Parkia platycephala } \\
\text { Benth. }\end{array}$ & Fava-de-bolota & $\mathrm{N}$ & 25 & 11,1 & 200 & 88,9 & 225 \\
\hline & $\begin{array}{c}\text { Paubrasilia echinata } \\
\text { (Lam.) Gagnon, H. C. } \\
\text { Lima \& G.P.Lewis }\end{array}$ & Pau-brasil & EC & 5 & 31,3 & 11 & 68,8 & 16 \\
\hline & $\begin{array}{l}\text { Plathymenia reticulata } \\
\text { Benth. }\end{array}$ & Vinhático & $\mathrm{N}$ & 0 & 0,0 & 132 & 100,0 & 132 \\
\hline & $\begin{array}{l}\text { Pterodon } \\
\text { emarginatusVogel }\end{array}$ & Sucupira-lisa & $\mathrm{N}$ & 1 & 3,1 & 31 & 96,9 & 32 \\
\hline & $\begin{array}{l}\text { Schizolobium parahyba } \\
\text { (Vell.) Blake }\end{array}$ & Guapuruvu & $\mathrm{EC}$ & 0 & 0,0 & 4 & 100,0 & 4 \\
\hline & $\begin{array}{l}\text { Senna siamea (Lam.) } \\
\text { H.S.Irwin \& Barneby }\end{array}$ & Sena & EB & 43 & 29,3 & 104 & 70,7 & 147 \\
\hline & $\begin{array}{l}\text { Stryphnodendron } \\
\text { adstringens (Mart.) } \\
\text { Coville }\end{array}$ & Barbatimão & $\mathrm{N}$ & 2 & 8,7 & 21 & 91,3 & 23 \\
\hline & Tachigali aurea Tul. & Carvoeiro & $\mathrm{N}$ & 0 & 0,0 & 41 & 100,0 & 41 \\
\hline & $\begin{array}{c}\text { Tachigali rubiginosa } \\
\text { (Mart. ex Tul.) Oliveira- } \\
\text { Filho }\end{array}$ & Cachamorra & $\mathrm{N}$ & 5 & 0,9 & 526 & 99,1 & 531 \\
\hline & Tamarindus indica $\mathrm{L}$. & Tamarindo & $\mathrm{EB}$ & 13 & 20,3 & 51 & 79,7 & 64 \\
\hline & $\begin{array}{l}\text { Vatairea macrocarpa } \\
\text { (Benth.) Ducke }\end{array}$ & Amargoso & $\mathrm{N}$ & 2 & 1,0 & 191 & 99,0 & 193 \\
\hline \multirow[b]{2}{*}{ Lamiaceae } & Aegiphila verticilata Vell. & Tamanqueiro & $\mathrm{N}$ & 0 & 0,0 & 1 & 100,0 & 1 \\
\hline & $\begin{array}{l}\text { Cinnamomum burmanni } \\
\text { (Ness \& T. Ness) Blume }\end{array}$ & Falsa-canela & $\mathrm{EB}$ & 1 & 50,0 & 1 & 50,0 & 2 \\
\hline \multirow{2}{*}{ Lauraceae } & Persea americana Mill. & Abacate & EB & 9 & 20,5 & 35 & 79,5 & 44 \\
\hline & Tectona grandis L.f. & Teca & $\mathrm{EB}$ & 0 & 0,0 & 3 & 100,0 & 3 \\
\hline \multirow{2}{*}{ Lecythidaceae } & Bertholletia excelsa Bonpl. & $\begin{array}{l}\text { Castanheira-do- } \\
\text { pará }\end{array}$ & EC & 1 & 100,0 & 0 & 0,0 & 1 \\
\hline & $\begin{array}{c}\text { Cariniana rubra Gardner } \\
\text { ex Miers }\end{array}$ & $\begin{array}{l}\text { Cachimbo-de- } \\
\text { macaco }\end{array}$ & $\mathrm{N}$ & 0 & 0,0 & 1 & 100,0 & 1 \\
\hline
\end{tabular}


Tabela 1 - Continuação ...

Table 1 - Continuation ...

\begin{tabular}{|c|c|c|c|c|c|c|c|c|}
\hline Família & Espécies & Nome Popular & Origem & Rua & P.O. & AV & P.O. & Total \\
\hline \multirow{3}{*}{ Lythraceae } & Lagerstroemia indica $\mathrm{L}$. & Extremosa & EB & 1 & 16,7 & 5 & 83,3 & 6 \\
\hline & $\begin{array}{c}\text { Physocalymma } \\
\text { scaberrimum Pohl }\end{array}$ & Cega-machado & $\mathrm{N}$ & 1 & 1,8 & 54 & 98,2 & 55 \\
\hline & Punica granatum $\mathrm{L}$. & Romã & $\mathrm{EB}$ & 0 & 0,0 & 2 & 100,0 & 2 \\
\hline \multirow{6}{*}{ Malpighiaceae } & $\begin{array}{l}\text { Byrsonima basiloba } \\
\text { A.Juss. }\end{array}$ & Murici-do-campo & $\mathrm{N}$ & 3 & 16,7 & 15 & 83,3 & 18 \\
\hline & $\begin{array}{c}\text { Byrsonima pachyphylla } \\
\text { A.Juss. }\end{array}$ & Murici-ferrugem & $\mathrm{N}$ & 0 & 0,0 & 151 & 100,0 & 151 \\
\hline & Byrsonima sericea DC. & Murici & $\mathrm{N}$ & 0 & 0,0 & 27 & 100,0 & 27 \\
\hline & $\begin{array}{l}\text { Byrsonima verbascifolia } \\
\text { (L.) DC. }\end{array}$ & Muricizão & $\mathrm{N}$ & 0 & 0,0 & 5 & 100,0 & 5 \\
\hline & $\begin{array}{c}\text { Lophanthera lactescens } \\
\text { Ducke }\end{array}$ & Lanterneiro & $\mathrm{EC}$ & 125 & 54,1 & 106 & 45,9 & 231 \\
\hline & $\begin{array}{c}\text { Malpighia emarginata } \\
\text { D.C. }\end{array}$ & Acerola & EB & 36 & 37,5 & 60 & 62,5 & 96 \\
\hline \multirow{10}{*}{ Malvaceae } & Apeiba tibourbou Aubl. & Escova-de-macaco & $\mathrm{N}$ & 0 & 0,0 & 1 & 100,0 & 1 \\
\hline & $\begin{array}{l}\text { Eriotheca gracilipes (K. } \\
\text { Schum) A. Robyns }\end{array}$ & Paineira-lisa & $\mathrm{N}$ & 4 & 3,5 & 109 & 96,5 & 113 \\
\hline & $\begin{array}{c}\text { Eriotheca pubescens } \\
\text { (Mart. \& Zucc.) Schott \& } \\
\text { Endl. }\end{array}$ & Paineira-peluda & $\mathrm{N}$ & 1 & 1,0 & 97 & 99,0 & 98 \\
\hline & Guazuma ulmifolia Lam. & Pau-pólvora & $\mathrm{N}$ & 3 & 33,3 & 6 & 66,7 & 9 \\
\hline & Hibiscus rosa-sinensis $\mathrm{L}$. & Hibisco & $\mathrm{EB}$ & 2 & 66,7 & 1 & 33,3 & 3 \\
\hline & $\begin{array}{l}\text { Luehea paniculata Mart. } \\
\text { \& Zucc. }\end{array}$ & Açoita-cavalo & $\mathrm{N}$ & 0 & 0,0 & 2 & 100,0 & 2 \\
\hline & Pachira aquatica Aubl. & Cacau-selvagem & EC & 26 & 59,1 & 18 & 40,9 & 44 \\
\hline & Pachira glabra Pasq. & Castanha-da-praia & EC & 2 & 66,7 & 1 & 33,3 & 3 \\
\hline & $\begin{array}{l}\text { Sterculia striata A.St.-Hil. } \\
\text { \& Naudin }\end{array}$ & $\begin{array}{l}\text { Chichá-do- } \\
\text { cerrado }\end{array}$ & $\mathrm{N}$ & 0 & 0,0 & 17 & 100,0 & 17 \\
\hline & $\begin{array}{c}\text { Theobroma grandiflorum } \\
\text { (Willd. ex Spreng.) } \\
\text { K.Schum. }\end{array}$ & Cupuaçu & $\mathrm{EC}$ & 0 & 0,0 & 5 & 100,0 & 5 \\
\hline \multirow{3}{*}{ Melastomataceae } & $\begin{array}{c}\text { Miconia albicans (Sw.) } \\
\text { Triana }\end{array}$ & Pixirica & $\mathrm{N}$ & 0 & 0,0 & 3 & 100,0 & 3 \\
\hline & Mouriri pusa Gardner & Puçá & $\mathrm{N}$ & 2 & 7,1 & 26 & 92,9 & 28 \\
\hline & $\begin{array}{l}\text { Pleomora granulosum } \\
\text { (Desr.) D. Don }\end{array}$ & Quaresmeira & EC & 2 & 100,0 & 0 & 0,0 & 2 \\
\hline
\end{tabular}

Ci. Fl., Santa Maria, v. 30, n. 2, p. 565-582, abr./jun. 2020 
Tabela 1 - Continuação ...

Table 1 - Continuation ...

\begin{tabular}{|c|c|c|c|c|c|c|c|c|}
\hline Família & Espécies & Nome Popular & Origem & Rua & P.O. & AV & P.O. & Total \\
\hline \multirow{3}{*}{ Meliaceae } & Azadirachta indica A. Juss & Niin-indiano & EB & 68 & 41,2 & 97 & 58,8 & 165 \\
\hline & Cedrela fissilis Vell. & Cedro & EC & 1 & 11,1 & 8 & 88,9 & 9 \\
\hline & $\begin{array}{c}\text { Swietenia macrophylla } \\
\text { King }\end{array}$ & Mogno & EC & 8 & 20,0 & 32 & 80,0 & 40 \\
\hline \multirow{6}{*}{ Moraceae } & $\begin{array}{c}\text { Artocarpus heterophyllus } \\
\text { Lam. }\end{array}$ & Jaca & EB & 5 & 13,5 & 32 & 86,5 & 37 \\
\hline & Ficus benjamina $\mathrm{L}$. & Ficus & EB & 48 & 78,7 & 13 & 21,3 & 61 \\
\hline & Ficus carica $\mathrm{L}$. & Figo & EB & 1 & 100,0 & 0 & 0,0 & 1 \\
\hline & Ficus natalensis Hochst. & $\begin{array}{l}\text { Figueira- } \\
\text { triangular }\end{array}$ & EB & 0 & 0,0 & 1 & 100,0 & 1 \\
\hline & Ficus sp. & Figueira & EC & 2 & 100,0 & 0 & 0,0 & 2 \\
\hline & Morus nigra $\mathrm{L}$. & Amora & EB & 18 & 27,3 & 48 & 72,7 & 66 \\
\hline Moringaceae & Moringa oleifera Lam & Acácia-branca & EB & 1 & 33,3 & 2 & 66,7 & 3 \\
\hline \multirow{10}{*}{ Myrtaceae } & $\begin{array}{l}\text { Callistemon viminalis (Sol. } \\
\text { ex Gaertn.) G. Don }\end{array}$ & Escova-de-garrafa & EB & 0 & 0,0 & 3 & 100,0 & 3 \\
\hline & Corymbia sp. & Eucalipto & EB & 19 & 6,7 & 263 & 93,3 & 282 \\
\hline & Eugenia uniflora $\mathrm{L}$. & Pitanga & $\mathrm{N}$ & 21 & 42,9 & 28 & 57,1 & 49 \\
\hline & $\begin{array}{c}\text { Myrcia splendens (Sw.) } \\
\text { DC. }\end{array}$ & Guamirim & $\mathrm{N}$ & 0 & 0,0 & 210 & 100,0 & 210 \\
\hline & $\begin{array}{c}\text { Plinia cauliflora (Mart.) } \\
\text { Kausel }\end{array}$ & Jabuticaba & EC & 2 & 20,0 & 8 & 80,0 & 10 \\
\hline & Psidium guajava $\mathrm{L}$. & Goiaba & EC & 71 & 31,3 & 156 & 68,7 & 227 \\
\hline & Psidium myrsinites DC. & Araçá-vermelho & $\mathrm{N}$ & 0 & 0,0 & 11 & 100,0 & 11 \\
\hline & $\begin{array}{l}\text { Syzygium cumini (L.) } \\
\text { Skeels }\end{array}$ & Jamelão & EB & 154 & 29,1 & 376 & 70,9 & 530 \\
\hline & $\begin{array}{l}\text { Syzygium jambos (L.) } \\
\text { Alston }\end{array}$ & Jambo-amarelo & EB & 13 & 41,9 & 18 & 58,1 & 31 \\
\hline & $\begin{array}{l}\text { Syzygium malaccense (L.) } \\
\text { Merr. \& L. M. Perry }\end{array}$ & Jambo-vermelho & EB & 218 & 88,6 & 28 & 11,4 & 246 \\
\hline Nyctaginaceae & $\begin{array}{l}\text { Bougainvillea glabra } \\
\text { Choisy }\end{array}$ & Primavera & EC & 20 & 46,5 & 23 & 53,5 & 43 \\
\hline \multirow{3}{*}{ Oxalidaceae } & Averrhoa bilinbi L. & Limãozinho & EB & 3 & 33,3 & 6 & 66,7 & 9 \\
\hline & Averrhoa carambola L. & Carambola & EB & 8 & 72,7 & 3 & 27,3 & 11 \\
\hline & $\begin{array}{c}\text { Bumchosia armeniaca } \\
\text { (Cav.) DC }\end{array}$ & Caferana & EB & 0 & 0,0 & 3 & 100,0 & 3 \\
\hline Pinaceae & Pinus sp. & Pinheiro & EB & 1 & 0,3 & 386 & 99,7 & 387 \\
\hline & & & & & & \multicolumn{3}{|c|}{$\begin{array}{l}\text { Continua ... } \\
\text { Continuation ... }\end{array}$} \\
\hline
\end{tabular}


Tabela 1 - Conclusão ...

Table 1 - Conclusion ...

\begin{tabular}{|c|c|c|c|c|c|c|c|c|}
\hline Família & Espécies & Nome Popular & Origem & Rua & P.O. & AV & P.O. & Total \\
\hline Podocarpaceae & $\begin{array}{c}\text { Podocarpus macrophyllus } \\
\text { (Thunb.) Sweet }\end{array}$ & Podocarpo & $\mathrm{EB}$ & 25 & 100,0 & 0 & 0,0 & 25 \\
\hline Proteaceae & $\begin{array}{l}\text { Macadamia integrifolia } \\
\text { Maid. \& Bet. }\end{array}$ & Macadamia & EB & 1 & 50,0 & 1 & 50,0 & 2 \\
\hline Rhamnaceae & Ziziphus joazeiro Mart. & Juazeiro & $\mathrm{EC}$ & 3 & 100,0 & 0 & 0,0 & 3 \\
\hline \multirow{4}{*}{ Rubiaceae } & $\begin{array}{l}\text { Ferdinandusa elliptica } \\
\text { (Pohl) Pohl }\end{array}$ & Brinco-d'agua & $\mathrm{N}$ & 0 & 0,0 & 12 & 100,0 & 12 \\
\hline & Genipa americana L. & Jenipapo & $\mathrm{N}$ & 2 & 3,4 & 57 & 96,6 & 59 \\
\hline & Morinda citrifolia L. & Noni & $\mathrm{EB}$ & 10 & 23,8 & 32 & 76,2 & 42 \\
\hline & $\begin{array}{l}\text { Tocoyena formosa (Cham. } \\
\text { \& Schltdl.) K.Schum. }\end{array}$ & Figo-de-cavalo & $\mathrm{N}$ & 0 & 0,0 & 8 & 100,0 & 8 \\
\hline \multirow{4}{*}{ Rutaceae } & Citrus aurantium L. & Laranja & $\mathrm{EB}$ & 1 & 7,1 & 13 & 92,9 & 14 \\
\hline & Citrus limon (L.) Osbeck & Limão & $\mathrm{EB}$ & 22 & 21,2 & 82 & 78,8 & 104 \\
\hline & Citrus trifoliata $\mathrm{L}$. & Poncirus & EB & 1 & 100,0 & 0 & 0,0 & 1 \\
\hline & $\begin{array}{c}\text { Murraya paniculata (L.) } \\
\text { Jack }\end{array}$ & Murta & EB & 113 & 84,3 & 21 & 15,7 & 134 \\
\hline \multirow[t]{2}{*}{ Sapindaceae } & $\begin{array}{c}\text { Magonia pubescens A.St.- } \\
\text { Hil. }\end{array}$ & Tinguí-do-cerrado & $\mathrm{N}$ & 0 & 0,0 & 2 & 100,0 & 2 \\
\hline & Sapindus saponaria L. & Sabãozinho & $\mathrm{N}$ & 78 & 65,0 & 42 & 35,0 & 120 \\
\hline \multirow{2}{*}{ Sapotaceae } & $\begin{array}{l}\text { Pouteria ramiflora (Mart.) } \\
\text { Radlk. }\end{array}$ & Abiu & $\mathrm{N}$ & 2 & 4,8 & 40 & 95,2 & 42 \\
\hline & $\begin{array}{c}\text { Pouteria torta (Mart.) } \\
\text { Radlk. }\end{array}$ & Curriola & $\mathrm{N}$ & 4 & 16,0 & 21 & 84,0 & 25 \\
\hline Simaroubaceae & $\begin{array}{c}\text { Simarouba versicolor } \\
\text { A.St.-Hil. }\end{array}$ & Mata-menino & $\mathrm{N}$ & 3 & 5,1 & 56 & 94,9 & 59 \\
\hline Solanaceae & $\begin{array}{c}\text { Solanum lycocarpum } \\
\text { A.St.-Hil. }\end{array}$ & Lobeira & $\mathrm{N}$ & 0 & 0,0 & 6 & 100,0 & 6 \\
\hline Urticaceae & $\begin{array}{c}\text { Cecropia pachystachya } \\
\text { Trécul }\end{array}$ & Embaúba & $\mathrm{N}$ & 3 & 9,4 & 29 & 90,6 & 32 \\
\hline \multirow{4}{*}{ Vochysiaceae } & Qualea grandiflora Mart. & $\begin{array}{l}\text { Pau-terra-folha- } \\
\text { grande }\end{array}$ & $\mathrm{N}$ & 0 & 0,0 & 141 & 100,0 & 141 \\
\hline & Qualea parviflora Mart. & $\begin{array}{l}\text { Pau-terra-folha- } \\
\text { miúda }\end{array}$ & $\mathrm{N}$ & 0 & 0,0 & 225 & 100,0 & 225 \\
\hline & $\begin{array}{c}\text { Salvertia convallariodora } \\
\text { A.St.-Hil. }\end{array}$ & Chapéu-de-couro & $\mathrm{N}$ & 0 & 0,0 & 137 & 100,0 & 137 \\
\hline & Vochysia sp. & Cambará & $\mathrm{N}$ & 0 & 0,0 & 40 & 100,0 & 40 \\
\hline
\end{tabular}

Fonte: Autores (2019)

Em que: P.O = Porcentagem de ocorrência; $\mathrm{AV}=$ Áreas verdes; $\mathrm{N}$ = Árvores nativas do Cerrado; $\mathrm{EC}$ = árvores exóticas ao Cerrado; $\mathrm{EB}=$ Árvores exóticas estrangeiras. 
A diversidade de espécies foi elevada $\left(H^{\prime}=4,046\right)$ e significativamente maior $(t=12,364$, $\mathrm{p}<0,001)$ nas áreas verdes $\left(\mathrm{H}^{\prime}=3,892\right)$ em relação às ruas $\left(\mathrm{H}^{\prime}=3,572\right)$.

Dentre as 10 espécies mais frequentes destaca-se o cajú Anacardium occidentale com 1.512 indivíduos, o pequi Caryocar brasiliense com 1.371, a manga Mangifera indica com 1.293, o oiti Licania tomentosa com 1.243 e o ipê-roxo Handroanthus impetiginosus com 832 indivíduos, sendo que dessas 10 espécies 4 são estrangeiras e 2 originárias de outros biomas brasileiros. Mais da metade do percentual total de indivíduos arbóreos das quadras analisadas estão incluídos nas 10 espécies mais abundantes (Figura 2).

Nas ruas das quadras urbanizadas, a maioria das espécies são exóticas ao Cerrado. O oiti Licania tomentosa foi a espécie mais frequente na arborização das ruas superando com ampla diferença as demais espécies. Nas áreas verdes, as árvores nativas foram as mais frequentes, com destaque para o pequi Caryocar brasiliense e o cajú Anacardium occidentale. Porém, a frequência de espécies exóticas nas áreas verdes foi elevada, incluindo espécies pouco recomendadas para arborização urbana como o eucalipto Corymbia sp. e o pinheiro Pinus sp. (Figura 2).

Figura 2 - Distribuição das dez espécies arbóreas mais frequentes nas ruas e áreas verdes das quadras residenciais urbanizadas de Palmas/TO

Figure 2 - Distribution of the ten most frequent arboreal species in the streets and green areas of urban residential blocks of Palmas/TO state

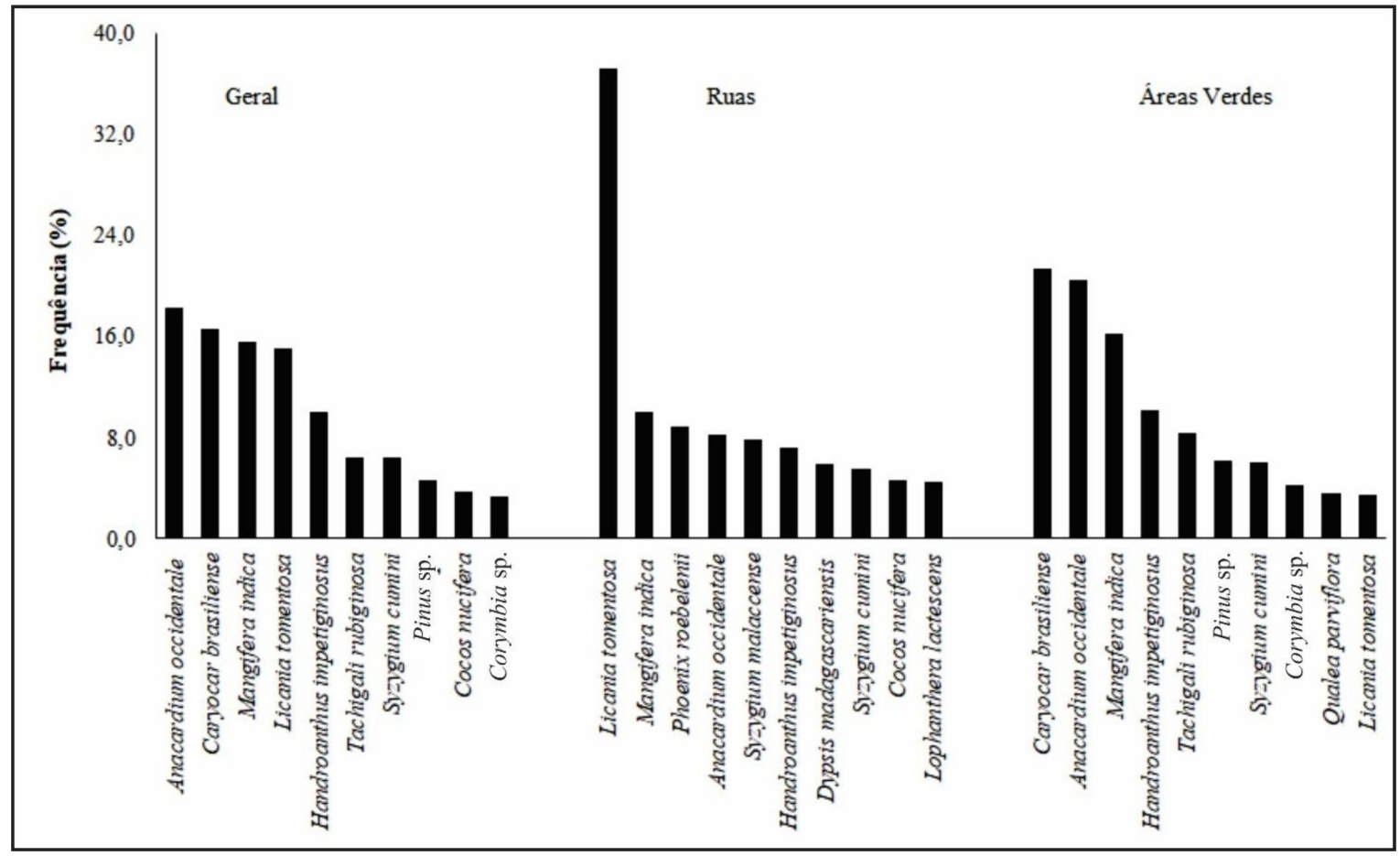

Fonte: Autores (2019)

\section{Discussão}

A riqueza e a diversidade de espécies na arborização das quadras residenciais urbanizadas de Palmas-TO é considerável, principalmente nas áreas verdes que contêm 92,04\% da riqueza específica das quadras urbanizadas e congrega mais de $70 \%$ das espécies arbóreas. Nessas áreas verdes a diversidade de espécies também é significativamente maior que nas ruas. As áreas 
verdes urbanas são responsáveis por múltiplas funções que promovem melhorias consideráveis no ambiente urbano, fornecendo benefícios ambientais, ecológicos, sociais, estéticos, recreativos e para a saúde (MCPHERSON; VAN DOORN; GOEDE, 2016). Não obstante, a cobertura arbórea das áreas verdes de muitas quadras de Palmas foi total ou parcialmente suprimida devido a políticas públicas equivocadas (ADORNO; FIGHERA, 2005) e de queimadas recorrentes nesses ambientes (MOURA; FERNANDEZ, 2012).

Segundo o Diagnóstico da Arborização Urbana de Palmas-TO (PALMAS, 2015), existe um défict de aproximadamente 100 mil árvores nas AVNEs. A ausência de cobertura arbórea é um dos fatores responsáveis pelo desconforto térmico (ABREU-HARBICH; LABAKI; MATZARAKIS, 2015) e formação de ilhas de calor (SANUSI et al., 2017) em áreas urbanas, situações já encontradas em Palmas-TO (PAZ, 2010), apesar de ser uma cidade relativamente jovem, planejada visando a preservação de áreas verdes para mitigar os efeitos do calor.

Nas ruas das quadras urbanizadas o déficit de arborização também é elevado, sendo estimado em cerca de 53.760 árvores (PALMAS, 2015). A carência de arborização e uma diversidade inferior à encontrada nas áreas verdes corrobora o padrão encontrado em outras cidades brasileiras (SANTOS; BERGALLO; ROCHA, 2008) ou estrangeiras (KURUNERI-CHITEPO; SHACKLETON, 2011), que apresentam um predomínio de espécies arbóreas exóticas nas vias.

No entanto, Hitchmough (2011) argumenta que as espécies exóticas, à exceção daquelas consideradas invasivas ou problemáticas, podem desempenhar um importante papel socioambiental nas cidades. Em Palmas-TO, apesar da apreciável riqueza de espécies nas ruas das quadras urbanizadas, também há o predomínio de espécies exóticas ao Cerrado, incluindo algumas espécies estrangeiras muito frequentes e de alto valor estético, como é o caso da palmeira fênix Phoenix roebelenii, da areca-locuba Dypsis madagascariensis ou a cica Cycas circinalis e o sagu Cycas revoluta, mas que pouco ou nada contribuem com a melhoria bioclimática em uma das cidades mais quentes do país.

Dentre as exóticas estrangeiras mais frequentes nas ruas das quadras de Palmas-TO está a mangueira Mangifera indica, que possui muitos atributos socioambientais, produzindo ótima sombra e frutos comestíveis, contudo, não recomenda-se seu plantio em calçadas devido às possibilidades de conflito com o calçamento, rede elétrica, mobilidade, limpeza urbana ou pela atração de insetos indesejados (MILANO; DALCIN, 2000). Em Palmas-TO, essa espécie foi amplamente propagada, seja pelo poder público municipal que distribuia mudas ou pela população que a plantou deliberadamente.

Outro padrão amplamente evidenciado em outras áreas urbanas é a elevada frequência de umas poucas espécies que acabam dominando a paisagem urbana. Em Palmas-TO, as 10 espécies mais frequentes nas quadras residenciais detém mais da metade do percentual de árvores, no entanto, duas delas o pequi Caryocar brasiliense e a cachamorra Tachigali rubiginosa são espécies autóctones, sendo o pequi uma das espécies mais importantes do Cerrado, possuindo um alto valor sociocultural, ambiental, ecológico e econômico, e uma das espécies mais abundantes em Palmas-TO (PALMAS, 2015), entretanto, a produção de mudas para arborização urbana ainda é inexistente na cidade. Por outro lado, a espécie mais frequente nas quadras residenciais é o cajú Anacardium occidentale, de fácil propagação e amplamente cultivado por ser uma espécie perene, de rápido crescimento, copa ampla e fruto comestível de alto valor nutritivo.

Nas quadras residenciais de Palmas-TO, aproximadamente $15 \%$ de sua superfície foi planejada como área verde não edificante (AVNE) com o objetivo de amenizar as elevadas temperaturas locais. Essas áreas verdes têm cumprido um papel socioambiental que vai além daquele para a qual foi planejada, trazendo melhorias consideráveis para o entorno. A arborização das áreas verdes das quadras de Palmas-TO possui múltipla importância. Das 182 espécies inventariadas, $36,3 \%$ podem ser utilizadas para alimentação humana, 58,8\% são úteis para a fauna de vertebrados e invertebrados e 70,3\% consideradas medicinais, usadas como fitoterápicos ou remédios caseiros (PINHEIRO; MARCELINO; MOURA, 2018). O predomínio de espécies nativas nas áreas verdes é altamente positivo sob diversos aspectos, seja prevenindo a homogeneização 
biótica ou dando suporte a uma maior diversidade de espécies (MORGENROTH et al., 2016). Em Palmas-TO, foi demonstrado ainda que a arborização nativa influencia positivamente a riqueza de aves, enquanto que essa relação é negativa quando comparado com a presença de espécies arbóreas exóticas (REIS; LÓPEZ-IBORRA; PINHEIRO, 2012).

O somatório de alguns fatores como o intenso processo de conversão antrópica do Cerrado pela agropecuária, que já alterou quase metade da cobertura vegetal do bioma e a taxa de urbanização que superou os 100\% nas últimas duas décadas (AZEVEDO et al., 2011) contribuem para a perda da diversidade biológica. Palmas-TO, a capital brasileira com a maior taxa de crescimento geométrico do país (IBGE, 2010), demanda ações urgentes visando à conservação da sua diversidade biológica. Infelizmente, na cidade ainda é incipiente a percepção do valor dado à vegetação nativa do Cerrado, que no aspecto sociocultural e ecológico, desempenha serviços ecossistêmicos mais relevantes que as espécies exóticas (GOMES-BAGGETHUN; BARTON, 2013). Além disso, informações sobre a importância do verde urbano incrementando o valor da propriedade, da saúde e do bem estar humano, a redução do consumo de energia e da poluição do ar ou a atenuação das enchentes (ESCOBEDO; KROEGER; WAGNER, 2011) devem ser amplamente difundidas para a sociedade, formadores de opinião e tomadores de decisão.

Reforçar os valores culturais e de pertencimento vinculados às espécies nativas e ouvir a opinião dos residentes locais são práticas não aplicadas pelos gestores locais. Enquanto cidades ao redor do mundo como Barcelona, Espanha (BARÓ et al., 2014), Compenhagen e Dinamarca (SJÖMAN et al., 2012) buscam alternativas para diversificar o verde urbano, priorizando espécies autóctones mais resilientes, com o intuito de mitigar os efeitos das mudanças climáticas, em Palmas-TO, onde as temperaturas são extremamente elevadas e a umidade relativa do ar baixa em grande parte do ano, as políticas públicas têm caminhado na direção contrária, permitindo a supressão indiscriminada de árvores nativas e a realização de práticas de gestão insustentáveis. Para que as áreas verdes e a arborização urbana cumpram efetivamente seu papel socioambiental e atenda as demandas da sociedade, faz-se necessária a urgente adoção de políticas públicas que protejam as espécies nativas e promovam a restauração dos ambientes naturais degradados em ambientes urbanos.

\section{Conclusão}

Palmas-TO se diferencia dos padrões urbanos vigentes, possuindo uma elevada diversidade de espécies arbóreas nativas nas áreas residenciais quando comparada a outros centros urbanos, o que está diretamente relacionado à presença das áreas verdes não edificantes. Nas ruas das quadras urbanizadas observa-se um processo avançando de substituição das espécies arbóreas nativas do Cerrado por espécies de outros biomas do Brasil e do exterior.

A elevada diversidade de espécies nativas tende a incrementar a integridade ecológica, porém é importante considerar os benefícios associados ao plantio de algumas espécies não nativas nas áreas urbanas, principalmente aquelas associadas a aspectos de identidade com a população, em grande parcela proveniente de outras regiões do Brasil.

A arborização das quadras residenciais de Palmas deverá ser considerada como um recurso multifuncional, proporcionando melhorias sociais, ambientais e econômicas. O manejo deve buscar o incremento da biodiversidade, priorizando a preservação das espécies autóctones e nativas do Cerrado, principalmente nas áreas verdes não edificantes onde é possível promover o adensamento arbóreo, maximizando os serviços ambientais e ecológicos promovidos pela arborização urbana. 


\section{Agradecimentos}

Agradecemos o apoio da Fundação de Apoio Científico e Tecnológico do Tocantins FAPTO, a Fundação Municipal de Meio Ambiente - FMA de Palmas-TO e a Lojas Havan.

\section{Referências}

ABREU-HARBICH, L. V.; LABAKI, L. C.; MATZARAKIS, A. Effect of tree planting design and tree species on human thermal confort in the tropics. Landscape and Urban Planning, Amsterdam, v. 138, p. 99-109, 2015.

ADORNO, L. F. M.; FIGHERA, D. R. A. Trajetória da política ambiental de Palmas enquanto capital ecológica. In: ALMEIDA, M. D. de (org.). Tantos cerrados. Goiânia: Vieira, 2005. v. 1. p. 205-223.

AZEVEDO, M. C. X. A. et al. Avaliação da taxa de urbanização do Bioma Cerrado através dos produtos DMSP-OLS: uma análise preliminar para os anos de 1992 a 2009. In: SIMPÓSIO BRASILEIRO DE SENSORIAMENTO REMOTO, 15., 2011. Anais [...]. Curitiba: INPE, 2011. p. 6757-6762.

BARGOS, D. C.; MATIAS, L. F. Áreas verdes urbanas: um estudo de revisão e proposta conceitual. Revista Brasileira de Arborização Urbana, Piracicaba, v. 6 n. 3, p. 172-188, 2011.

BARÓ, F. et al. Contribution to ecosystem services to air quality and climate change mitigation policies: the case of urban forests in Barcelona, Spain. AMBIO, Suécia, v. 43 n. 4, p. 466-479, 2014.

ESCOBEDO, F. J.; KROEGER, T.; WAGNER, J. E. Urban forests and pollution mitigation: analyzing ecosystem services and disservices. Environmental Pollution, [s. 1.], v. 159, n. 8/9, p. 207-2087, aug./sep. 2011.

GOMES-BAGGETHUN, E.; BARTON, D. N. Classifying and valuing ecosystem services for urban planning. Ecological Economics, [s. 1.], v. 86, p. 235-245, 2013.

HITCHMOUGH, J. Exotic plants and plantings in the sustainable, design urban landscape. Landscape and Urban Planning, Amsterdam, v. 100, p. 380-382, 2011.

HUTCHESON, K. A test for comparing diversities based on the Shannon formula. Journal of Theoretical Biology, [s. 1.], v. 29, p. 151-154, 1970.

IBGE. Censo demográfico 2010. Rio de Janeiro, [2010]. Disponível em: http://cidades.ibge.gov. br/. Acesso em: 07 ago. 2019.

JARDIM BOTÂNICO (Rio de Janeiro, RJ). Flora do Brasil 2020 em construção. Rio de Janeiro, [2018]. Disponível em: http://floradobrasil.jbrj.gov.br/. Acesso em: 12 nov. 2018.

KURUNERI-CHITEPO, C.; SHACKLETON, C. M. The distribution, abundance and composition of street trees in selected towns of Eastern Cape, South Africa. Urban Forestry and Urban Greening, Amsterdam, v. 10, p. 247-254, 2011.

LEWINSOHN, T. M.; PRADO, P. I. Biodiversidade Brasileira: síntese do estado atual do conhecimento. São Paulo: Contexto, 2002.176 p.

LORENZI, H. Árvores brasileiras: manual de identificação e cultivo de plantas arbóreas nativas 
do Brasil. 2. ed. Nova Odessa: [s. n.], 2002. v. 1. 384 p.

LORENZI, H. Árvores brasileiras: manual de identificação e cultivo de plantas arbóreas nativas do Brasil. 4. ed. Nova Odessa: [s. n.], 2014. v. 2. 384 p.

MAGURRAN A. E. Medindo a diversidade biológica. Curitiba: Editora da UFPR, 2011. 261 p.

MCPHERSON, E. G.; VAN DOORN, N.; GOEDE, J. Structure, function and value of street trees in California, USA. Urban forestry \& urban greening, Amsterdam, v. 17, p. 104-115, 2016.

MILANO, M. S.; DALCIN, E. Arborização de vias públicas. Rio de Janeiro: Fundação Parques e Jardins, 2000.

MORGENROTH, J. et al. Urban tree diversity - taking stock and looking ahead. Urban Forestry and Urban Greening, Amsterdam, v. 15, p. 1-5, 2016.

MORO, M. F.; WESTERKAMP, C.; DE ARAÚJO, F. S. How much importance is given to native plants in cities treescape? A case study in Fortaleza, Brazil. Urban Forestry and Urban Greening, Amsterdam, v. 13, p. 365-374, 2014.

MOURA, G. M. G.; FERNANDEZ, F. N. Problemas socioambientais e estrutura institucional da gestão urbana em Palmas (TO). Revista Desenvolvimento Regional, Santa Cruz do Sul, v. 17, n. 2, p. 33-55,2012.

PALMAS (TO). Prefeitura. Diagnóstico da arborização urbana de Palmas. Palmas, 2015. 372 p.

PAZ, L. H. F. A influência da vegetação sobre o clima urbano de Palmas-TO. 2010. Dissertação (Mestrado em Arquitetura e Urbanismo) - Universidade de Brasília, Brasília, 2010.

PINHEIRO, R. T.; MARCELINO, D. G.; MOURA, D. R. Espécies arbóreas de uso múltiplo e sua importância na conservação da biodiversidade nas áreas verdes urbanas de Palmas, Tocantins. Desenvolvimento e Meio Ambiente, Curitiba, v. 49, p. 1-22, 2018.

REIS, E.; LÓPEZ-IBORRA, G. M.; PINHEIRO, R. T. Changes in bird species richness through different levels of urbanization: Implications for biodiversity conservation and garden design in Central Brazil. Landscape Urban Plannig, [s. 1.], v. 107, p. 31-42, 2012.

SANTOS, A. R.; BERGALlO, H. G.; ROCHA, C. F. D. Paisagem urbana alienígena. Ciência Hoje, Rio de Janeiro, v. 41, p. 68-70, 2008.

SANUSI, R. et al. Microclimate benefits that different street trees provide to sidewalk pedestrians relate to differences in Plant Area Index. Landscape Urban Plannig, [s. 1.], v. 157, p. 502-511, 2017.

SJÖMAN, H. et al. Diversification of the urban forest - Can we afford to exclude exotic tree species? Urban Forestry and Urban Greening, [s. 1.], v. 18, p. 237-241, 2012.

TEIXEIRA, L. F. C. A formação de Palmas. Revista da UFG, Goiânia, v. 6, p. 91-99, 2009.

THE PLANT LIST. Version 1.1. [S. 1.], 2013. Disponível em: http://www.theplantlist.org/. Acesso em: 17 nov. 2018. 